\title{
Equilíbrio ácido-básico de embriões e pintos de corte em momentos críticos da incubação e submetidos a diferentes períodos de transferência para o nascedouro
}

\author{
[Acid-base balance of embryos and broiler chicks in critical moments of incubation \\ and submitted to different periods of transfer to the hatcher] \\ V.M. Barbosa ${ }^{1}$, N.C. Baião ${ }^{2}$, J.S.R. Rocha ${ }^{3}$, P.M.M. Mendes ${ }^{3}$, L.J.C. Lara $^{2}$, M.A. Pompeu ${ }^{3}$, F.O.P. \\ Leme $^{2}$, P.C. Cardeal ${ }^{3}$, N.R.S. Martins ${ }^{2}$, R.C. Leite ${ }^{2}$ \\ ${ }^{1}$ Pós-doutoranda - INCT - Pecuária - Escola de Veterinária - UFMG - Belo Horizonte, MG \\ ${ }^{2}$ Escola de Veterinária - Universidade Federal de Minas Gerais - EV-UFMG - Belo Horizonte, MG \\ ${ }^{3}$ Aluno de pós-graduação - Escola de Veterinária - EV-UFMG - Belo Horizonte, MG
}

\begin{abstract}
RESUMO
Foram analisados os níveis de $\mathrm{pCO}_{2}, \mathrm{pO}_{2}, \mathrm{pH}$ e $\mathrm{HCO}_{3}{ }^{-}$de embriões e pintos de corte provenientes de matrizes novas e velhas, nos momentos anteriores à bicagem interna e externa da casca e ao nascimento, submetidos a diferentes períodos de transferência para as condições ambientais dos nascedouros. Os tratamentos foram definidos pela idade da matriz (33 e 63 semanas) e pela transferência para o nascedouro (aos 15, 17 e 19 dias). O delineamento experimental foi em parcelas subdivididas, sendo a parcela os três momentos de transferência e a subparcela as duas idades das matrizes. Foram utilizadas seis repetições para cada tratamento, e o embrião ou o pinto foi considerado uma repetição. Os dados normais e homogêneos foram submetidos às análises de variância, e as médias comparadas pelos testes $\mathrm{F}$, de Tukey e SNK. Embriões cujos ovos foram transferidos aos 15 dias para o nascedouro apresentaram melhor equilíbrio ácido-básico durante as fases pré-natal e perinatal. Durante o último terço da incubação, independentemente das diferentes condições ambientais às quais os embriões são submetidos e da idade da matriz, há capacidade de resposta fisiológica que permite uma estabilidade no equilíbrio ácido-básico dos pintos após a eclosão.
\end{abstract}

Palavras-chave: incubação, equilíbrio ácido-básico, hemogasometria, idade da ave, frangos de corte

\begin{abstract}
We analyzed the levels of $\mathrm{pCO}_{2}, \mathrm{pO}_{2}, \mathrm{pH}$ and $\mathrm{HCO}_{3}^{-}$in embryos and chicks from young and older breeders, in the moments before internal pipping, external pipping and at hatch and submitted to different periods in the environmental conditions of hatchers. The treatments were defined by breeder age (33 and 63 weeks) and transfer to the hatcher (at 15, 17 and 19 days). The experimental design was split plots with three periods in the hatcher and the plots were the two breeder ages. We used six replicates per treatment and the embryo or chick was considered a repetition. The normal data forms were submitted to analysis of variance and means were compared by F, Tukey and SNK tests. Embryos transferred at 15 days to the hatcher had better acid-base balance during the pre-and perinatal phases. During the last third of incubation, regardless of the different environmental conditions which the embryos are subjected and breeder age, there is physiological responsiveness that allows for stability in acid-base balance of the chicks after hatching.
\end{abstract}

Keywords: incubation, acid-base balance, blood gas analysis, bird age, broilers

Recebido em 16 de agosto de 2012

Aceito em 20 de dezembro de 2013

E-mail: vmichalsky@gmail.com 


\section{INTRODUÇÃO}

O estágio de desenvolvimento do embrião de ave se divide em duas fases: a pré-natal, compreendida do início da incubação até a ocorrência da bicagem interna, quando a respiração ocorre através da área vasculosa e posteriormente da corioalantoide; e a perinatal, que vai da bicagem interna até a bicagem externa da casca. A partir da eclosão, a ventilação pulmonar é estabilizada e os pulmões assumem definitivamente a função respiratória (Romanoff, 1960; Tullet e Deeming, 1982; Tazawa e Whittow, 2000).

Aproximadamente no $19^{\circ}$ dia de incubação, aumenta a necessidade de oxigênio, e a respiração por transporte difusivo exercido pela corioalantoide não pode suprir essa exigência, apresentando uma hipóxia que estimula o embrião à bicagem interna e à eclosão. Este estímulo pode ser também neuroendócrino ou devido às mudanças do equilíbrio ácido-básico ou pressão de gases, e ainda existe a possibilidade de uma combinação de todos estes fatores (Christensen, 1995; Rondón e Murakami, 1998). O período entre a bicagem interna e a externa oscila entre cinco e 12 horas, e a hipóxia neste período pode ter influência tanto na sobrevivência do embrião como nos processos metabólicos e no desenvolvimento pós-eclosão (Onagbesan et al., 2007).

Para a ocorrência da eclosão, devem ser atingidos os seguintes requisitos: perda adequada de água pelo embrião, aumento da concentração de $\mathrm{CO}_{2}$ na câmara de ar e diminuição da concentração de $\mathrm{O}_{2}$. A condutância da casca determina todas estas condições, mantendo um papel fisiológico importante para o metabolismo embrionário, principalmente na fase final de incubação e no estabelecimento dos valores normais do equilíbrio ácido-básico no sangue (O’Dea et al., 2004; Hamidu et al., 2007; Bamelis et al., 2008).

O'Dea et al. (2004) reportaram que o metabolismo embrionário também aumenta com a idade da matriz. Estes autores avaliaram a produção de calor, gás carbônico e consumo de oxigênio pelos embriões de três linhagens de matrizes pesadas com idades de 33 e 38 semanas. Todas as análises demonstraram valores significativamente maiores para os embriões provenientes das matrizes com idade mais avançada.

Rowlett e Simkiss (1989) observaram que o aumento contínuo da demanda metabólica de $\mathrm{O}_{2}$ pelo embrião ocasiona queda no $\mathrm{pO}_{2}$ no sangue durante todo o período final de incubação e só é revertida quando a respiração pulmonar é estabilizada. Segundo os autores, as primeiras medições de gases em sangue de embriões demonstraram também acúmulo de $\mathrm{CO}_{2}$ e acidose respiratória progressiva neste período final de desenvolvimento, ocorrendo aumento de $\mathrm{HCO}_{3}{ }^{-}$no plasma como forma de compensação do $\mathrm{pH}$ sanguíneo.

Hamidu et al. (2007) pesquisaram a produção de $\mathrm{CO}_{2}$ durante o período de incubação em linhagens de matrizes pesadas. Esta produção aumentou principalmente após o $12^{\circ}$ dia de incubação, no entanto, após a bicagem interna, a produção de $\mathrm{CO}_{2}$ continuou aumentando significativamente, evidenciando maior exigência metabólica no processo de nascimento.

Os parâmetros sanguíneos $\mathrm{pCO}_{2}, \mathrm{pO}_{2}, \mathrm{pH}$ e $\mathrm{HCO}_{3}^{-}$, em embriões de matrizes pesadas com 32, 42 e 65 semanas de idade, foram avaliados no momento da bicagem interna e à eclosão por Yalçin et al. (2008). Nessas fases, o valor de $\mathrm{pH}$ sanguíneo dos embriões de matrizes com 65 semanas foi significativamente menor quando comparado às idades mais novas, que foram semelhantes entre si. Esta situação se repetiu no caso das concentrações de $\mathrm{HCO}_{3}{ }^{-}$à eclosão, entretanto, anteriormente, na bicagem interna, as idades não tiveram influência neste parâmetro. A $\mathrm{pO}_{2}$ e a $\mathrm{pCO}_{2}$ no sangue dos embriões de matrizes de diferentes idades não revelaram diferenças significativas tanto no momento da bicagem interna quanto à eclosão, porém foi

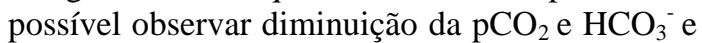
elevação da $\mathrm{pO}_{2}$ após o nascimento.

Durante a incubação, os ovos são comumente transferidos da incubadora para o nascedouro aos 18 ou 19 dias de incubação. Na câmara de eclosão, os fatores físicos da incubação são alterados para maior ventilação, maior umidade, menor temperatura, e a viragem dos ovos é descontinuada, com o objetivo de adequar as condições ambientais da máquina de acordo com as necessidades fisiológicas do embrião. A antecipação da transferência pode ser uma 
alternativa para aumentar a capacidade de incubação nas indústrias ou para flexibilizar o fluxo de produção. Entretanto, não há pesquisas atuais que revelam o comportamento do equilíbrio ácido-básico de embriões e pintos, provenientes de matrizes com diferentes idades, submetidos a um maior período nos nascedouros, ainda que a homeostase destes possa ser fator de impacto no desempenho pós-eclosão.

$\mathrm{O}$ objetivo desta pesquisa foi analisar os níveis de $\mathrm{pCO}_{2}, \mathrm{pO}_{2}, \mathrm{pH}$ e $\mathrm{HCO}_{3}{ }^{-}$de embriões e pintos de corte provenientes de matrizes novas e velhas, em momentos críticos do desenvolvimento, como os anteriores à bicagem interna e externa da casca e ao nascimento, transferidos aos 15, 17 e 19 dias para as condições ambientais dos nascedouros.

\section{MATERIAL E MÉTODOS}

Os ovos foram obtidos de dois lotes de matrizes pesadas Cobb® com idades de 33 e 63 semanas, produzidos no mesmo dia. Os ovos foram desinfetados pelo método de fumigação com paraformoldeído. Realizou-se a seleção dos ovos, eliminando-se aqueles considerados não incubáveis (sujos, trincados, quebrados, pequenos, com duas gemas e deformados). Em seguida, os ovos foram colocados em bandejas próprias para incubação, com capacidade para 96 ovos cada. Foram utilizadas 18 bandejas de incubação, totalizando 1.728 ovos para cada tratamento. Durante três dias, os ovos foram armazenados em temperatura média de $19,1^{\circ} \mathrm{C}$ e umidade relativa do ar de $84,3 \%$. Antes do início da incubação, os ovos foram submetidos a um pré-aquecimento, na temperatura média de $28,2^{\circ} \mathrm{C}$ por 10 horas. Foi utilizada uma incubadora modelo Casp® $\mathrm{CMg} 125 \mathrm{E}$, de estágio múltiplo, com capacidade para 124.416 ovos. A máquina de incubação teve seu termostato regulado para manter constante a temperatura do bulbo seco em $99,3^{\circ} \mathrm{F}$ e a temperatura do bulbo úmido em $84^{\circ} \mathrm{F}$, correspondendo ao teor de UR de $62 \%$.

Os tratamentos foram definidos pela idade da matriz e pelos momentos de transferência para os nascedouros, da seguinte maneira:

A: ovos de matrizes novas (33 semanas), transferidos para os nascedouros aos 15 dias. $B$ : ovos de matrizes velhas (63 semanas), transferidos para os nascedouros aos 15 dias. $C$ : ovos de matrizes novas (33 semanas), transferidos para os nascedouros aos 17 dias. $D$ : ovos de matrizes velhas (63 semanas), transferidos para os nascedouros aos 17 dias. $E$ : ovos de matrizes novas (33 semanas), transferidos para os nascedouros aos 19 dias. $F$ : ovos de matrizes velhas (63 semanas), transferidos para os nascedouros aos 19 dias.

Com 15, 17 e 19 dias de incubação (de acordo com os tratamentos), os ovos foram retirados da máquina de incubação e transferidos para a câmara de eclosão. De acordo com os períodos de permanência nos nascedouros, as bandejas com os ovos dos tratamentos foram colocadas em três máquinas de eclosão modelo Casp® G21 E, com capacidade para 20.736 ovos. As três máquinas de eclosão estavam posicionadas em sequência em uma mesma sala. Nessas máquinas, os termostatos de todos os nascedouros foram programados para manter a temperatura do bulbo seco em $98^{\circ} \mathrm{F}$ e a temperatura do bulbo úmido em $84^{\circ} \mathrm{F}$, correspondendo ao teor de UR de $65 \%$. Os carrinhos com as bandejas foram posicionados na parte da frente dos três nascedouros e as bandejas foram colocadas de forma intercalada, de acordo com as diferentes idades das matrizes. Os demais espaços das máquinas foram preenchidos com ovos dos mesmos lotes de matrizes e com a mesma idade de incubação, os quais não fizeram parte desta pesquisa. A retirada dos pintos dos nascedouros ocorreu com 504 horas (21 dias) de incubação.

As análises que permitiram avaliar os níveis sanguíneos de $\mathrm{pH}, \mathrm{PaCO}_{2}, \mathrm{PaO}_{2}, \mathrm{HCO}_{3}^{-}$dos embriões e pintos foram realizadas por meio do aparelho analisador clínico portátil i-STAT® e cartuchos modelo Cartridge CG8+ (Abott Laboratories®-USA).

Os momentos para as coletas das amostras são descritos a seguir.

1) Nos embriões dos tratamentos $A e B$, as coletas foram realizadas no momento anterior à transferência para o nascedouro com 15 dias de incubação. 2) Nos embriões dos tratamentos $\mathrm{C} e$ $D$, as coletas foram realizadas no momento anterior à transferência para o nascedouro com 17 dias de incubação. 3) Nos embriões dos tratamentos $E e F$, as coletas foram realizadas no momento anterior à transferência para o 
nascedouro com 19 dias de incubação. Nestas idades (15, 17 e 19 dias), os embriões ainda não haviam bicado a membrana interna da casca. 4) Nos embriões de todos os tratamentos foi feita uma segunda coleta aos 20 dias de incubação, embora nesta idade os embriões já tivessem rompido a membrana corioalantoide e a membrana interna da casca. $\mathrm{O}$ momento escolhido para as coletas foi quando já havia indícios do início do processo de bicagem da casca, porém sem rompimento da membrana externa da casca. 5) Nos pintos de todos os tratamentos, foi realizada uma terceira coleta aos 21 dias de incubação, ou seja, logo após a eclosão.

Para as coletas das amostras de sangue dos embriões com 15 e 17 dias de idade, previamente, os ovos foram examinados individualmente em um ovoscópio para a delimitação da região da câmara de ar. Em seguida, com o auxílio de uma tesoura, um pedaço de, aproximadamente, $1 \mathrm{~cm}^{2}$ de casca foi retirado desta região. Com acesso à membrana interna, uma gota de glicerina foi espalhada nesta camada para a visualização dos vasos sanguíneos da membrana corioalantoide. Rapidamente, cerca de $250 \mu \mathrm{L}$ de sangue arterial foram retirados com tubos capilares após pequena inserção na artéria com agulha $27 \mathrm{G} 1 / 2$. . O método dessas coletas foi adaptado ao descrito por Piper et al. (1980). No caso da coleta das amostras de sangue dos embriões com 19 dias de idade, os ovos também foram individualmente examinados em um ovoscópio para a delimitação da região da câmara de ar. Em seguida, com o auxílio de uma tesoura, um pedaço de aproximadamente $1 \mathrm{~cm}^{2}$ foi retirado na região oposta à câmara de ar, para acesso à artéria umbilical. Logo em seguida, cerca de $0,5 \mathrm{~mL}$ de sangue arterial foi retirado com seringa de $1 \mathrm{~mL}$ e agulha $27 \mathrm{G} 1 / 2$. . Nos embriões com 20 dias de incubação e nos pintos recém-eclodidos, as coletas foram realizadas por meio de punção cardíaca pelo lado esquerdo do coração, onde aproximadamente $0,5 \mathrm{~mL}$ de sangue arterial foi retirado com seringa de $3 \mathrm{~mL}$ e agulha 30G. Em cada momento de coleta, foram utilizadas amostras de seis embriões ou pintos por tratamento, retirados ao acaso das bandejas. Imediatamente após cada coleta individual, cerca de $100 \mu \mathrm{L}$ de sangue foram inseridos nos cartuchos, que automaticamente fizeram a leitura dos parâmetros mencionados.
O delineamento experimental foi em parcelas subdivididas, sendo as parcelas os três períodos de permanência no nascedouro (seis, quatro e dois dias de incubação) e a subparcela as duas idades das matrizes. Foram utilizadas seis repetições para cada tratamento, e o embrião foi considerado uma repetição. A normalidade e a homocedasticidade dos dados foram verificadas pelo teste de Lillliefors e Bartlett. Os dados normais e homogêneos foram submetidos às análises de variância, e as médias comparadas pelos testes F, de Tukey e SNK segundo Sampaio (2002), utilizando-se o programa SAEG, versão 9.1 (Sistema..., 2005).

A metodologia utilizada neste experimento foi aprovada pelo Comitê de Ética em Experimentação Animal da Universidade Federal de Minas Gerais - CETEA, sob protocolo $\mathrm{n}^{\circ}$ $247 / 10$.

\section{RESULTADOS E DISCUSSÃO}

O pH sanguíneo dos embriões aos 15, 17 e 19 dias de incubação (ou seja, no momento em que foram transferidos para o nascedouro) foi semelhante $(\mathrm{P}>0,05)$, independentemente da idade das matrizes (Tab. 1). Estes resultados demonstram que não houve alteração de $\mathrm{pH}$ sanguíneo dos embriões de matrizes novas e velhas durante $\mathrm{o}$ período anterior à bicagem interna, independentemente de eles estarem com 15, 17 ou 19 dias de incubação. Aos 20 dias de incubação, após a bicagem interna e no momento anterior à bicagem externa da casca, independentemente da idade da matriz, embriões que estavam nos nascedouros desde os 15 dias apresentaram pH sanguíneo mais elevado $(\mathrm{P} \leq 0,05)$ quando comparados aos embriões cujos ovos estavam no nascedouro desde os 17 e 19 dias, sendo estes tratamentos semelhantes entre si. Nesta fase, o pH sanguíneo dos embriões provenientes das matrizes com 33 semanas foi maior $(\mathrm{P} \leq 0,05)$ do que o $\mathrm{pH}$ sanguíneo dos embriões das reprodutores com 63 semanas, independentemente da idade de transferência dos ovos da incubadora para o nascedouro. $\mathrm{O} \mathrm{pH}$ sanguíneo dos pintos após a eclosão não foi influenciado pelas idades das matrizes e pelos diferentes períodos de permanência no nascedouro $(\mathrm{P}>0,05)$.

Conforme demonstrado na Tab. 1, é possível observar que, na fase perinatal dos embriões 
(momento compreendido entre a bicagem interna e a bicagem externa da casca), ocorreu uma queda de $\mathrm{pH}$ sanguíneo em todos os tratamentos. Neste estágio, os embriões que foram transferidos aos 15 dias de incubação tiveram os valores de $\mathrm{pH}$ sanguíneo significativamente $(\mathrm{p} \leq 0,05)$ maiores do que os embriões que foram transferidos aos 17 ou 19 dias para o nascedouro; ou seja, estes embriões tiveram uma queda menos acentuada de $\mathrm{pH}$ sanguíneo, independentemente da idade da matriz. Os embriões provenientes de matrizes novas, também neste momento, tinham valores significativamente $(p \leq 0,05)$ mais elevados quando comparados aos embriões de matrizes velhas, demonstrando uma queda de $\mathrm{pH}$ sanguíneo menor, independentemente dos períodos de permanência nos nascedouros. Após a eclosão, os pintos de todos os tratamentos elevaram seu pH sanguíneo, e, nesta ocasião, as diferenças ocorridas antes da bicagem externa da casca deixaram de existir, resultando em $\mathrm{pH}$ sanguíneos semelhantes nos pintos de todos os tratamentos.
Segundo Rowlett e Kimkiss (1989), as primeiras medições de hemogasometria em embriões de aves demonstram uma acidose respiratória progressiva até o final do desenvolvimento. Os valores da $\mathrm{PaCO}_{2}$ e $\mathrm{PaO}_{2}$, apresentados nas Tab. 2 e 3, demonstram que o aumento da $\mathrm{PaCO}_{2}$ e a queda de $\mathrm{PaO}_{2}$, que ocorreram progressivamente durante o desenvolvimento embrionário até momentos anteriores à eclosão, justificam os resultados de $\mathrm{pH}$ sanguíneo. A partir da eclosão, quando estes níveis foram estabilizados, o $\mathrm{pH}$ sanguíneo se elevou, voltando aos valores próximos dos iniciais. Em relação à idade da matriz, os resultados deste experimento corroboram os obtidos por Yalçin et al. (2008), que avaliaram embriões de matrizes pesadas com 32, 42 e 65 semanas no momento da bicagem interna e à eclosão. Nestes dois momentos, o valor de $\mathrm{pH}$ sanguíneo dos embriões descendentes de matrizes com 65 semanas foi significativamente menor quando comparado às idades mais novas, que tiveram resultados semelhantes entre si. Os autores também observaram que após a eclosão ocorreu aumento da $\mathrm{PaO}_{2}$ e queda da $\mathrm{PaCO}_{2}$

Tabela 1. Valores médios de pH sanguíneo de embriões e pintos em diferentes momentos de incubação, de acordo com a idade da matriz e o período de transferência para o nascedouro

\begin{tabular}{|c|c|c|c|c|}
\hline \multirow{2}{*}{$\begin{array}{l}\text { Idade da matriz } \\
\text { (semanas) }\end{array}$} & \multicolumn{3}{|c|}{ Período de transferência para o nascedouro (dias) } & \multirow{2}{*}{ Média } \\
\hline & 15 & 17 & 19 & \\
\hline \multicolumn{5}{|c|}{ Antes da bicagem interna da casca ${ }^{x}$} \\
\hline 33 & 7,52 & 7,54 & 7,54 & 7,53 \\
\hline 63 & 7,57 & 7,58 & 7,60 & 7,58 \\
\hline Média & 7,55 & 7,56 & 7,57 & $\mathrm{CV}=1,3 \%$. \\
\hline \multicolumn{5}{|c|}{ Antes da bicagem externa da casca ${ }^{y}$} \\
\hline 33 & 7,48 & 7,35 & 7,36 & $7,39 \mathrm{~A}$ \\
\hline 63 & 7,40 & 7,30 & 7,31 & $7,34 \mathrm{~B}$ \\
\hline Média & $7,44 \mathrm{a}$ & $7,33 \mathrm{~b}$ & $7,34 \mathrm{~b}$ & $\mathrm{CV}=1,1 \%$. \\
\hline \multicolumn{5}{|c|}{ Após eclosão ${ }^{x}$} \\
\hline 33 & 7,55 & 7,55 & 7,54 & 7,55 \\
\hline 63 & 7,54 & 7,52 & 7,53 & 7,53 \\
\hline Média & 7,54 & 7,54 & 7,53 & $\mathrm{CV}=0,9 \%$. \\
\hline
\end{tabular}

Médias seguidas de letras distintas, minúsculas na linha e maiúsculas na coluna, são diferentes pelos testes $\mathrm{F}^{\mathrm{x}}$ e ds Tukey $^{\mathbf{y}}(\mathrm{P} \leq 0,05)$.

De acordo com a Tab. 2, a $\mathrm{PaCO}_{2}$ dos embriões aos 15 dias de incubação foi menor $(\mathrm{P} \leq 0,05)$ que a $\mathrm{PaCO}_{2}$ de embriões aos 17 e 19 dias, sendo estes tratamentos semelhantes entre si, independentemente da idade da matriz. Embriões provenientes de matrizes novas e velhas apresentaram $\mathrm{PaCO}_{2}$ semelhante, independentemente da idade deles na incubação (P>0,05). Quando a incubação estava no $20^{\circ}$ dia, ou seja, quando os embriões estavam na fase perinatal, a $\mathrm{PaCO}_{2}$ dos embriões transferidos aos 15 dias foi menor $(\mathrm{P} \leq 0,05)$ que a $\mathrm{PaCO}_{2}$ dos 
embriões transferidos aos 17 e 19 dias, sendo estes tratamentos semelhantes entre si, independentemente da idade da matriz. Nesta fase, embriões de matrizes novas e velhas apresentaram $\mathrm{PaCO}_{2}$ semelhante $(\mathrm{P}>0,05)$, independentemente do período nos nascedouros. Nos pintos recém-eclodidos, houve interação entre a idade da matriz e os períodos da transferência. Quando a permanência no nascedouro foi de seis dias, pintos originados de matrizes novas apresentaram menor $(\mathrm{P} \leq 0,05)$ $\mathrm{PaCO}_{2}$ do que os de matrizes velhas. Nos demais períodos de permanência nos nascedouros, não houve diferença $(\mathrm{P}>0,05)$ na $\mathrm{PaCO}_{2}$ entre as idades das matrizes. Os períodos de permanência nos nascedouros não influenciaram $(\mathrm{P}>0,05)$ a $\mathrm{PaCO}_{2}$ de pintos recém-eclodidos, provenientes de matrizes novas e matrizes velhas.

A Tab. 2 demonstra que embriões tiveram um aumento em sua $\mathrm{PaCO}_{2}$ até momentos antes da bicagem da casca. Após a eclosão, esses níveis diminuíram. Os resultados condizem com as afirmações de Hamidu et al. (2007). Segundo estes autores, durante o desenvolvimento embrionário, ocorre aumento significativo na produção de $\mathrm{CO}_{2}$ mesmo após a bicagem interna da casca, quando esta produção revela seus maiores níveis, evidenciando maior exigência metabólica do processo de nascimento. Anteriormente, Tona et al. (2003) e De Smit et al. (2006), ao avaliarem a câmara de ar momentos antes e após a bicagem interna, obtiveram aumento significativo da pressão de $\mathrm{CO}_{2}$ nesta região entre estes dois momentos.

As informações da literatura, aliadas aos resultados obtidos neste experimento, mostram que, até a completa transição da respiração corioalantoide para a respiração pulmonar, ocorre uma hipercapnia nestes embriões que pode estar associada ao estímulo para a eclosão. Foi observado que embriões cujos ovos foram transferidos aos 15 dias tiveram menor $\mathrm{PaCO}_{2}$ até o momento da bicagem externa da casca quando comparados aos outros tratamentos. Estes embriões permaneceram maior tempo nos nascedouros, sob condições de maior ventilação e, consequentemente, maior suprimento de $\mathrm{O}_{2}$ e menor concentração de $\mathrm{CO}_{2}$ nos ambientes da máquina.

Tabela 2. Valores médios de $\mathrm{PaCO}_{2}(\mathrm{mmHg})$ de embriões e pintos em diferentes momentos de incubação, de acordo com a idade da matriz e o período de transferência para o nascedouro

\begin{tabular}{|c|c|c|c|c|}
\hline \multirow{2}{*}{$\begin{array}{l}\text { Idade da matriz } \\
\text { (semanas) }\end{array}$} & \multicolumn{3}{|c|}{ Período de transferência para o nascedouro (dias) } & \multirow{2}{*}{ Média } \\
\hline & 15 & 17 & 19 & \\
\hline \multicolumn{5}{|c|}{ Antes da bicagem interna da casca ${ }^{x}$} \\
\hline 33 & 25,4 & 35,5 & 37,9 & $32,9 \mathrm{~A}$ \\
\hline 63 & 29,8 & 36,9 & 39,9 & $35,5 \mathrm{~A}$ \\
\hline Média & $27,6 \mathrm{~b}$ & $36,2 \mathrm{a}$ & $38,9 \mathrm{a}$ & $\mathrm{CV}=23,8 \%$. \\
\hline \multicolumn{5}{|c|}{ Antes da bicagem externa da casca ${ }^{x}$} \\
\hline 33 & 40,4 & 45,4 & 49,1 & $45,0 \mathrm{~A}$ \\
\hline 63 & 41,2 & 47,5 & 47,8 & $45,5 \mathrm{~A}$ \\
\hline Média & $40,8 \mathrm{~b}$ & $46,5 \mathrm{a}$ & $48,5 \mathrm{a}$ & $\mathrm{CV}=15,4 \%$ \\
\hline \multicolumn{5}{|c|}{ Após eclosão ${ }^{y}$} \\
\hline 33 & $21,7 \mathrm{Ba}$ & $26,4 \mathrm{Aa}$ & $24,0 \mathrm{Aa}$ & \\
\hline 63 & $26,2 \mathrm{Aa}$ & $24,7 \mathrm{Aa}$ & $23,7 \mathrm{Aa}$ & $\mathrm{CV}=11,4 \%$ \\
\hline
\end{tabular}

Médias seguidas de letras distintas, minúsculas na linha e maiúsculas na coluna, são diferentes pelos testes $\mathrm{SNK}^{\mathrm{x}}$ e de Tukey ${ }^{\mathrm{y}}(\mathrm{P} \leq 0,05)$.

De acordo com os dados da Tab. 3, antes da bicagem interna da casca, independentemente da idade da matriz, a $\mathrm{PaO}_{2}$ dos embriões diminuiu à medida que os embriões foram aumentando de idade $(\mathrm{P} \leq 0,05)$, evidenciando um progressivo "déficit" de oxigênio, que pode ser justificado pelo aumento do consumo com o crescimento. Nesta fase, independentemente da idade dos embriões no momento da transferência para os nascedouros, embriões provenientes de reprodutoras novas e velhas tiveram $\mathrm{PaO}_{2}$ semelhantes $(\mathrm{P}>0,05)$. Aos 20 dias de incubação 
(antes da bicagem externa da casca), a $\mathrm{PaO}_{2}$ dos embriões que permaneceram no nascedouro a partir dos 15 dias foi maior $(\mathrm{P} \leq 0,05)$ quando comparada aos embriões que permaneceram no nascedouro a partir de 17 e 19 dias, sendo estes tratamentos semelhantes entre si, independentemente da idade da matriz. Nesta fase, embriões de matrizes novas apresentaram maior nível de $\mathrm{PaO}_{2} \quad(\mathrm{P} \leq 0,05)$ quando comparados aos embriões de matrizes mais velhas, independentemente do período de transferência para o nascedouro. Como os ovos e os pintos de matrizes velhas são mais pesados, provavelmente estes embriões maiores tiveram maior produção de calor, maior consumo de oxigênio, revelando, consequentemente, maior hipóxia neste momento. Ao se avaliarem conjuntamente as respostas de $\mathrm{pH}$ sanguíneo e $\mathrm{PaO}_{2}$ dos tratamentos no período perinatal, é possível verificar que embriões de matrizes mais novas, cujas $\mathrm{PaO}_{2}$ foram maiores $\quad(\mathrm{P} \leq 0,05), \quad$ também tiveram $\mathrm{pH}$ sanguíneo significativamente maiores $(\mathrm{P} \leq 0,05)$ quando comparados às matrizes velhas, independentemente do momento da transferência. A $\mathrm{PaO}_{2}$ nos pintos após a eclosão não foi influenciada pela idade da matriz e pelo período de permanência no nascedouro $(\mathrm{P}>0,05)$.

A Tab. 3 demonstra a diminuição progressiva da $\mathrm{PaO}_{2}$ no decorrer do desenvolvimento embrionário até momentos antes da bicagem da casca. Após a eclosão, a $\mathrm{PaO}_{2}$ se elevou em todos os tratamentos e atingiu níveis semelhantes, coincidindo com a transição para a respiração pulmonar. Estes dados corroboram os de Christensen (1995), Rondón e Murakami (1998) e Onagbesan et al. (2007), os quais observaram que aproximadamente no $19^{\circ}$ dia de incubação ocorre aumento da necessidade de oxigênio pelos embriões, e a respiração por difusão através da membrana corioalantoide não pode suprir esta deficiência, sendo a hipóxia ocorrida nesta fase um estímulo para a bicagem interna e para a eclosão.

Tabela 3. Valores médios de $\mathrm{PaO}_{2}(\mathrm{mmHg})$ de embriões e pintos em diferentes momentos de incubação, de acordo com a idade da matriz e o período de transferência para o nascedouro

\begin{tabular}{|c|c|c|c|c|}
\hline \multirow{2}{*}{$\begin{array}{l}\text { Idade da matriz } \\
\text { (semanas) }\end{array}$} & \multicolumn{3}{|c|}{ Período de transferência para o nascedouro (dias) } & \multirow{2}{*}{ Média } \\
\hline & 15 & 17 & 19 & \\
\hline \multicolumn{5}{|c|}{ Antes da bicagem interna da casca ${ }^{x}$} \\
\hline 33 & 55,6 & 44,2 & 32,5 & $44,4 \mathrm{~A}$ \\
\hline 63 & 54,9 & 42,6 & 30,8 & $42,8 \mathrm{~A}$ \\
\hline Média & $55,8 \mathrm{a}$ & $43,4 \mathrm{~b}$ & $31,7 \mathrm{c}$ & $\mathrm{CV}=33,6 \%$. \\
\hline \multicolumn{5}{|c|}{ Antes da bicagem externa da casca ${ }^{y}$} \\
\hline 33 & 26,3 & 21,7 & 22,1 & $23,4 \mathrm{~A}$ \\
\hline 63 & 23,6 & 19,8 & 19,3 & $20,9 \mathrm{~B}$ \\
\hline Média & $25,0 \mathrm{a}$ & $20,8 \mathrm{~b}$ & $20,7 \mathrm{~b}$ & $\mathrm{CV}=13,7 \%$ \\
\hline \multicolumn{5}{|c|}{ Após eclosão ${ }^{z}$} \\
\hline 33 & 58,2 & 56,4 & 56,8 & 57,1 \\
\hline 63 & 56,4 & 57,6 & 56,8 & 57,6 \\
\hline Média & 57,3 & 57,0 & 57,8 & $\mathrm{CV}=4,4 \%$. \\
\hline
\end{tabular}

Médias seguidas de letras distintas, minúsculas na linha e maiúsculas na coluna, são diferentes pelos testes $\mathrm{F}^{\mathrm{X}}$, de Tukey $^{\mathrm{y}}$ e $\mathrm{F}^{\mathrm{z}}(\mathrm{P} \leq 0,05)$.

Antes da bicagem interna da casca, a concentração sanguínea de $\mathrm{HCO}_{3}{ }^{-}$dos embriões com 15 dias foi menor $(\mathrm{P} \leq 0,05)$ que a dos embriões com 17 e 19 dias, sendo estes semelhantes entre si, independentemente da idade da matriz (Tab. 4). Estes resultados mostram que a função tamponante do bicarbonato frente a um distúrbio ácido-básico pode ter sido menos necessária nos embriões com 15 dias, visto que nesta fase eles tiveram menor $\mathrm{PaCO}_{2}$ quando comparados aos outros tratamentos, em relação aos momentos de transferência (Tab. 2). Os embriões de matrizes novas apresentaram $\mathrm{HCO}_{3}{ }^{-}$semelhante $(\mathrm{P}>0,05)$ aos embriões de matrizes velhas, independentemente da idade deles no momento 
da transferência, o que também ocorreu para a variável $\mathrm{PaCO}_{2}$. Antes da bicagem externa da casca (aos 20 dias de incubação), a concentração sanguínea de $\mathrm{HCO}_{3}{ }^{-}$dos embriões que permaneceram no nascedouro desde os 15 dias foi menor $(\mathrm{P} \leq 0,05)$ do que os embriões que permaneceram no nascedouro desde $17 \mathrm{e}$ 19 dias, sendo estes semelhantes entre si, independentemente da idade da matriz. Nesta fase, embriões de matrizes com diferentes idades apresentaram concentração de $\mathrm{HCO}_{3}{ }^{-}$semelhante $(\mathrm{P}>0,05)$, independentemente do período de transferência para o nascedouro. Este resultado também mostrou que a função tamponante do bicarbonato teve comportamento semelhante e nos mesmos tratamentos da análise de $\mathrm{PaCO}_{2}$ (Tab. 2). Nos pintos recém-eclodidos, houve interação entre a idade da matriz e os períodos de transferência para o nascedouro. Nas permanências no nascedouro durante seis e quatro dias, correspondentes às transferências aos 15 e 17 dias, respectivamente, pintos originados de matrizes novas apresentaram maior $(\mathrm{P} \leq 0,05)$ valor de $\mathrm{HCO}_{3}{ }^{-}$do que os de matrizes velhas. Este efeito da idade não foi observado na permanência dos ovos por dois dias no nascedouro (transferidos aos 19 dias). Em matrizes novas, pintos com permanência de seis e quatro dias apresentaram maior $(\mathrm{P} \leq 0,05)$ $\mathrm{HCO}_{3}{ }^{-}$do que os de ovos que permaneceram dois dias no nascedouro. Em matrizes velhas, pintos originados de ovos com seis dias na máquina de eclosão apresentaram menor $(\mathrm{P} \leq 0,05) \mathrm{HCO}_{3}{ }^{-}$do que aqueles com quatro e dois dias no nascedouro.

Após a eclosão, a $\mathrm{PaCO}_{2}$ e a concentração sanguínea de $\mathrm{HCO}_{3}{ }^{-}$dos embriões provenientes das matrizes novas que permaneceram seis dias no nascedouro foram significativamente menores $(\mathrm{P} \leq 0,05)$ quando comparadas aos embriões de matrizes velhas no mesmo período na máquina de eclosão. Nos outros tratamentos, a função tamponante do bicarbonato mostrou-se diferenciada para manter o equilíbrio ácidobásico evidenciado nos pintos após o nascimento, mediante a associação dos parâmetros de $\mathrm{pH}$ sanguíneo, $\mathrm{PaCO}_{2}$ e $\mathrm{PaO}_{2}$ (Tab. 4).

Foi possível verificar que as concentrações sanguíneas de $\mathrm{HCO}_{3^{-}}$durante a incubação acompanharam as tendências das $\mathrm{PaCO}_{2}$. Estas observações corroboram as obtidas por Rowlett e Kimkiss (1989), Bruggeman et al. (2007) e Yalçin et al. (2008), que, ao avaliarem o equilíbrio ácido-básico do embrião em desenvolvimento, demonstraram a ação tamponante de $\mathrm{HCO}_{3}$ - como tentativa de reduzir o pH frente a situações de hipóxia e/ou hipercapnia.

Tabela 4. Valores médios das concentrações sanguíneas de $\mathrm{HCO}_{3}{ }^{-}(\mathrm{mmol} / \mathrm{L})$ de embriões e pintos em diferentes momentos de incubação, de acordo com a idade da matriz e o período de transferência para o nascedouro

\begin{tabular}{|c|c|c|c|c|}
\hline \multirow{2}{*}{$\begin{array}{l}\text { Idade da matriz } \\
\text { (semanas) }\end{array}$} & \multicolumn{3}{|c|}{ Período de transferência para o nascedouro (dias) } & \multirow{2}{*}{ Média } \\
\hline & 15 & 17 & 19 & \\
\hline \multicolumn{5}{|c|}{ Antes da bicagem interna da casca } \\
\hline 33 & 27,8 & 30,3 & 30,6 & $29,6 \mathrm{~A}$ \\
\hline 63 & 25,9 & 29,0 & 29,8 & $28,3 \mathrm{~A}$ \\
\hline Média & $26,9 \mathrm{~b}$ & $29,7 \mathrm{a}$ & $30,2 \mathrm{a}$ & $\mathrm{CV}=8,3 \%$ \\
\hline \multicolumn{5}{|c|}{ Antes da bicagem externa da casca } \\
\hline 33 & 31,9 & 36,7 & 35,7 & $34,8 \mathrm{~A}$ \\
\hline 63 & 29,7 & 34,5 & 34,1 & $32,8 \mathrm{~A}$ \\
\hline Média & $30,8 \mathrm{~b}$ & 35,6 a & $34,9 \mathrm{a}$ & $\mathrm{CV}=10,1 \%$ \\
\hline \multicolumn{5}{|c|}{ Após eclosão } \\
\hline 33 & $22,6 \mathrm{Aa}$ & $23,1 \mathrm{Aa}$ & $21,0 \mathrm{Ab}$ & \\
\hline 63 & $19,0 \mathrm{Bb}$ & $20,5 \mathrm{Ba}$ & $20,6 \mathrm{Aa}$ & $\mathrm{CV}=4,5 \%$. \\
\hline
\end{tabular}

Médias seguidas de letras distintas, minúsculas na linha e maiúsculas na coluna, são diferentes pelo teste Tukey $(\mathrm{P} \leq 0,05)$. 


\section{CONCLUSÕES}

Durante o último terço da incubação, os embriões demonstram ter respostas fisiológicas às diferentes condições de temperatura, umidade relativa do ar, ventilação e viragem aos quais são submetidos. Essas respostas permitem que, independentemente da idade da matriz ou dos diferentes períodos em que os embriões permanecem no nascedouro, ocorra uma estabilidade após a eclosão, tornando possível transferir os ovos para o nascedouro aos 15, 17 ou 19 dias de incubação, sem afetar o equilíbrio ácido-básico dos pintos.

\section{AGRADECIMENTOS}

À Granja Pif Paf, ao INCT-Pecuária, ao CNPq e à Fapemig.

\section{REFERÊNCIAS}

BAMELIS, F.R.; DE KETELAERE, B.; MERTENS, K. et al. Measuring the conductance of eggshells using the acoustic resonance technique and optical transmission spectra. Comput. Electron. Agric., v.62, p.35-40, 2008.

BRUGGEMAN, V.; WITTERS, A.; DE SMIT, L. et al. Acid-base balance in chicken embryos (Gallus domesticus) incubated under high $\mathrm{CO}_{2}$ concentrations during the first 10 days of incubation. Respir. Physiol. Neurobiol., v.159, p.147-154, 2007.

CHRISTENSEN, V.L. Factors affecting hatchability of turkey embryos. Poult. Avian Biol. Rev., v.6, p.71-82, 1995.

DE SMIT, L.; BRUGGEMAN, V.; TONA, J.K. et al. Embryonic developmental plasticity of the chick: Increased $\mathrm{CO}_{2}$ during early stages of incubation changes the developmental trajectories during prenatal and postnatal growth. Comp. Biochem. Physiol., v.145, p.166-175, 2006.

HAMIDU, J.A.; FASENKO, G.M.; FEDDES, J.J.R. et al. The effect of broiler breeder genetic strain and parent flock age on eggshell condutance and embryonic metabolism. Poult. Sci., v.86, p.2420-2432, 2007.
O’DEA, E.E.; FAZENKO, G.M.; FEDDES, J.J.R. et al. Investigating the eggshell condutance and embryonic metabolismo of modern and unselected domestic avian genetic strains at two flock ages. Poult. Sci., v.83, p.2059-2070, 2004.

ONAGBESAN, O.; BRUGGEMAN, V.; DE SMIT, L. et al. Gas exchange during storage and incubation of Avian eggs: effects on embryogenesis, hatchability, chick quality and posthatch growth. World Poultry Sci. J., v.63, p.557573, 2007.

PIIPER, J.; TAZAWA, H.; AR, A. et al. Analysis of chorioallantoic gas exchange in the chick embryo. Respir. Physiol., v.39, p.273-284, 1980.

ROMANOFF, A.L. (Ed). The avian embryo. New York: MACMILLAN COMPANY, 1960. 1305p.

RONDÓN, E.O.O.; MURAKAMI, A.E. Fatores que interferem no desenvolvimento embrionário e seus efeitos nos problemas metabólicos pós-eclosão em frangos de corte. Acta Sci., v.20, p.373-382, 1998.

ROWLETT, K.; SIMKISS, K. Respiratory gases and acid-base balance in shell-less avian embryos. J. Exp. Biol., v.143, p.529-536, 1989.

SAMPAIO, I.B.M. Estatística aplicada à experimentação animal. 2. ed. Belo Horizonte: FEPMVZ, 2002. 265p.

SISTEMA de análises estatísticas e genéticas. Versão 9.1. Viçosa: UFV, 2005.

TAZAWA, H.; WHITTOW, G.C. Incubation physiology. In: WHITTOW, G.C. Sturkie's Avian Physiology. 5 ed. London: ACADEMIC PRESS ,2000. p.617-634.

TONA, K.; ONAGBESAN, O.; DE KETELAERE, B.; DECUYPERE, E. et al. Effects of turning duration during incubation on corticosterone and thyroid hormone levels, gas pressure in air cell, chick quality, and juvenile growth. Poult. Sci., v.82, p.1947-1979, 2003.

TULLETT, S.G.; DEEMING, D.C. The relationship between eggshell porosity and oxigen consumption of the embryo in domestic fowl. Comp. Biochem. Physiol., v.72, p.529-533, 1982.

YALCIN, S.; ÇABUK, M.; BRUGGEMAN, V. et al. Acclimation to heat during incubation. 1. Embryonic morphological traits, blood biochemistry, and hatching performance. Poult. Sci., v.87, p.1219-1228, 2008. 